\title{
Bathing Newborn In Bimanese Tradition And Its Implication Toward Health
}

\author{
Ade Wulandari ${ }^{1}$, Abdul Haris ${ }^{2}$
}

1,2 Prodi D3 Keperawatan Bima Poltekkes Mataram

\section{Article Info}

\section{Article History:}

Accepted May 20th 2018

\section{Key words:}

Bathing, baby

Newborn

Tradition

Bima

\begin{abstract}
Background: Child care practices and parenting are still influenced by some habits that are considered as the basic needs of individuals or groups called cultures. An interesting phenomenon is the practice of newborn care by Bimanese by following tradition that is inherited from generation to generation. These child care practices include self-care hygiene of newborns, known as Kandeu Li, i. Kandeu Li'i is the tradition of bathing the baby for a long time, even the child gets shiver and cyanosis. Objective: to get a description of the tradition of self-care of newborns by Bimanese. Method: data were obtained through descriptive study conducted in the working area in the Asakota Public Health Service of Bima City on 25 families who were taking care of newborns encountered in the research period. Data collection was carried out by interview and observation method. Result: Observation results showed that $80 \%$ of respondents soaked the baby more than 10 minutes when the baby was bathed, $84 \%$ of the respondents did an additional tradition after the baby was bathed. The results of the interviews revealed that the majority of respondents said they follow the tradition of bathing the baby from inherited tradition and the reason of the respondent soaked the baby and did an additional tradition after bathing is to make baby can sleep more soundly and not easily surprised. Conclusion: Tradition and beliefs of most Bimanese about the newborn's self-care hygiene has high risk and harmful for the health and safety of the baby. Suggestion: As part of a professional health worker, the nurse needs to conduct home visits for families who will have babies to prepare parenting skills.
\end{abstract}

\section{PENDAHULUAN}

Perawatan bayi baru lahir sangat besar kontribusinya terhadap pertumbuhan dan perkembangan serta status kesehatan dalam periode kehidupan bayi selanjutnya. Praktik dalam pemenuhan kebutuhan nutrisi, perawatan kesehatan, monitoring pertumbuhan dan perkembangan serta perawatan kebersihan diri bayi yang baik akan berbanding lurus dengan status kesehatan bayi.

Praktik perawatan dan pola asuh anak oleh keluarga ataupun masyarakat saat ini masih dipengaruhi oleh keyakinan terhadap kenyamanan dalam melakukan kebiasaan yang sudah dikenal untuk memenuhi

Corresponding author:

Ade Wulandari 
kebutuhan dasar individu atau kelompok yang disebut sebagai budaya (Taylor1989 dalam Sudiharto, 2007). Terutama pada periode postpartum, masa ini merupakan periode dimana terjadi perubahan peran bagi setiap anggota keluarga. Masa transisi menjadi seorang ibu merupakan fenomena dimana setiap budaya memiliki ekspetasi dan dukungan yang berbeda bagi setiap ibu dalam melewati masa transisi ini. Wanita yang baru menjadi ibu merasa bahwa mereka akan mengikuti keyakinan dan melaksanakan tradisi berdasarkan budaya (Missal, 2013).

Fenomena yang menarik adalah praktik perawatan bayi baru lahir oleh masyarakat Bima dengan tata cara mengikuti tradisi yang diwariskan secara turun temurun. Praktik perawatan anak ini diantaranya adalah berkaitan dengan perawatan kebersihan diri bayi baru lahir yang dikenal dengan istilah Kandeu Li,i. Kandeu Li'i yaitu tradisi memandikan bayi baru lahir dengan cara bayi direndam air dalam waktu yang lama, bahkan sampai anak menggigil dan sianosis. Tradisi ini biasanya dilakukan oleh keluarga ataupun dukun yang membantu persalinan. Masyarakat yang melakukan kandeu Li,i meyakini praktik ini dapat menguatkan fisik bayi baru lahir. Praktik Kandeo Li,i dapat berisiko menyebabkan bayi berada dalam keadaan hipotermi, yaitu suatu keadaan suhu tubuh yang berada di bawah rentang suhu tubuh normal yang dapat berisiko merugikan kesehatan bayi.

Banyak praktik perawatan bayi baru lahir yang masih terikat dengan budaya tertentu dan untuk memperoleh praktik perawatan yang ideal menjadi tidak mungkin. Dalam situasi seperti ini, intervensi harus dinegosiasi dengan keluarga untuk mengidentifikasi perilaku yang dapat diterima (Neonatal Mortality formative research working group, 2008). Menurut konsep keperawatan Transkultural dengan Sunrise Model, praktik kesehatan berbasis budaya yang dapat merugikan kesehatan perlu mendapatkan intervensi tenaga kesehatan melalui strategi restrukturisasi tradisi (Sudiharto, 2007).

\section{METODE}

Data dipeproleh melalui studi deskriptif untuk mendapatkan gambaran mengenai tradisi perawatan kebersihan diri bayi baru lahir oleh masyarakat Bima. Studi dilakukan di wilayah kerja Puskesmas Asakota Kota Bima pada 25 keluarga yang sedang merawat bayi baru lahir yang dijumpai dalam kurun waktu penelitian. Pengumpulan data dilakukan melalui metode wawancara dan observasi.

Wawancara dilakukan pada keluarga untuk mendapatkan persepsi keluarga terhadap tradisi yang dilakukan. Observasi dilakukan saat keluarga memandikan bayi dan untuk melihat kondisi bayi setelah dimandikan. Lembar observasi dan pedoman wawancara digunakan sebagai instrument dalam pengumpulan data.

Untuk mendapatkan gambaran secara menyeluruh dari data yang telah dikumpulkan, data selanjutnya diolah dan dianalisis menggunakan metode statistik univariat.

\section{HASIL}

\section{Hasil Observasi}

Lama waktu untuk memandikan bayi

Tabel 1.1 Distribusi Responden Di Wilayah Kerja PKM Asakota Kota Bima Tahun 2016, $\mathrm{n}=25$

\begin{tabular}{lcc}
\hline \multicolumn{1}{c}{ Indikator } & $\mathrm{F}$ & $\%$ \\
\hline Lama waktu & & \\
memandikan & & \\
- Kurang dari 10 menit & 5 & 20 \\
- Lebih dari 10 menit & 20 & 80 \\
\hline $\begin{array}{l}\text { Melakukan tradisi } \\
\text { - Ya }\end{array}$ & 21 & 84 \\
- Tidak & 4 & 16 \\
\hline $\begin{array}{l}\text { Kondisi Bayi tanda } \\
\text { - Ada tanda hipotermi }\end{array}$ & 20 & 80 \\
- Tidak ada tanda \\
hipotermi
\end{tabular}

Hasil penelitian menunjukkan bahwa 20 responden $(80 \%)$ memandikan bayi dalam 
waktu lebih dari 10 menit dan 5 responden (20\%) memandikan bayi dalam waktu kurang dari 10 menit. 80\% bayi mengalami tanda-tanda hipotermi setelah dimandikan,

Hasil penelitian menunjukkan bahwa 21 responden (84\%) melakukan tradisi tambahan setelah memandikan bayi dan 4 responden (16\%) bayi tidak melakukan tradisi tambahan.

Hasil penelitian menunjukkan bahwa 20 bayi (80\%) mengalami tanda-tanda hipotermi dan 5 bayi (20\%) tidak mengalami tanda-tanda hipotermi setelah dimandikan.

\section{Hasil Wawancara}

Sumber informasi tentang cara
memandikan bayi

Distribusi Responden berdasarkan sumber informasi tentang cara memandikan bayi di Wilayah Kerja PKM Asakota Kota Bima Tahun 2016

\begin{tabular}{ccc}
\hline Indikator & F & $\%$ \\
\hline Sumber informasi & & \\
- Tenaga kesehatan & 4 & 16 \\
- Tradisi keluarga & 21 & 84 \\
Total & 25 & 100 \\
\hline
\end{tabular}

Pada tabel tersebut terlihat bahwa 4 responden (16\%) mendapatkan informasi tentang cara memandikan bayi dari tenaga kesehatan dan 21 responden (84\%) mendapatkan informasi dari tradisi keluarga.

\section{Persepsi responden terhadap tradisi merendam bayi}

Sebagian besar responden (80\%) mengatakan bahwa bayi harus dimandikan dengan cara direndam dalam waktu yang cukup lama agar bayi dapat tidur dengan nyenyak, tidak rewel serta agar fisik bayi lebih kuat dan kebal terhadap sakit.

\section{Persepsi responden terhadap tradisi tambahan setelah bayi dimandikan}

Tradisi tambahan yang dilakukan setelah bayi dimandikan adalah dengan cara mengangkat bayi di udara dalam beberapa kali gerakan. Sebagian besar responden (86\%) mengatakan alasan melakukan tradisi ini adalah agar bayi tidak mudah kaget.

\section{PEMBAHASAN}

Bayi yang baru lahir belum membutuhkan perawatan kebersihan diri yang berlebihan sehingga tidaklah susah untuk menjaga kebersihannya. Memandikan bayi setelah kelahiran memiliki risiko yang serius akibat dingin, dan sebenarnya dapat ditunda hingga beberapa hari (Newell \& Meadow, 2005). Hasil observasi terhadap tradisi memandikan bayi di Kecamatan Asakota menunjukkan bahwa sebagian besar responden merendam bayi dalam waktu yang relatif lama yaitu lebih dari 15 menit, dalam rentang waktu antara 20 sampai dengan 30 menit. Keluarga mengatakan bayi perlu direndam dengan jumlah air yang cukup dan waktu yang lama agar bayi dapat tidur nyenyak dan lebih lama serta diyakini dapat menjadikan tubuh bayi lebih berisi. Hasil pengamatan saat bayi dimandikan, rata-rata bayi mulai menggigil setelah sepuluh menit direndam dalam air. Namun demikian, bayi masih terus direndam hingga dirasa cukup. Standar kecukupan yang dijadikan acuan oleh sebagian besar responden adalah bila bayi sudah menunjukkan tanda-tanda hipotermi, yaitu menggigil dan sianosis. Setelah bayi selesai direndam dalam air, tradisi yang dilakukan selanjutnya adalah mengayunayun bayi beberapa kali di udara. Keluarga meyakini bahwa dengan diayun-ayun setelah mandi, bayi tidak akan mudah kaget. Tradisi mengayun bayi ini sangat berisiko menyebabkan bayi telepas dari pegangan sehingga dapat menyebabkan cidera.

Bayi umur 0 sampai 28 hari memiliki kebutuhan tidur selama 15 sampai dengan 16 jam. Pada siang hari bayi menghabiskan 
waktu sekitar 9 jam untuk tidur dan 7 sampai 8 jam di malam hari (Wong, 2003). Pola tidur bayi dipengaruhi oleh terpenuhinya kebutuhan makan. Bila kebutuhan makan telah terpenuhi maka bayi akan tertidur (Widyastuti \& Widyani, 2008). Oleh karena itu, keluarga perlu diberikan pemahaman bahwa kebutuhan tidur dan pertumbuhan fisik bayi tidak berhubungan dengan lamanya bayi direndam dalam air selama dimandikan. Demikian juga halnya dengan beberapa refleks primitive pada bayi baru lahir yang persepsikan oleh keluarga sebagai masalah karena dianggap sebagai kaget yang dirasakan oleh bayi. Refleks primitive pada bayi baru lahir ini adalah respon yang normal dan akan hilang dengan sendirinya seiring dengan perkembangan bayi (Wong, 2003).

Berdasarkan hasil wawancara dalam studi ini diketahui bahwa responden lebih banyak mengikuti tradisi secara turun temurun dalam tata cara perawatan kebersihan diri bayi dan hanya sebagian kecil yang memperoleh informasi dari tenaga kesehatan. Banyak praktik perawatan bayi baru lahir yang masih terikat dengan budaya tertentu dan untuk memperoleh praktik perawatan yang ideal menjadi tidak mungkin. Dalam situasi seperti ini, intervensi harus dinegosiasi dengan keluarga untuk mengidentifikasi perilaku yang dapat diterima (Neonatal Mortality formative research working group, 2008).

Tim kesehatan memegang peranan penting dalam meningkatkan kesehatan bayi baru lahir dengan peran dan fungsinya masingmasing. Kesinambungan asuhan dari pusat pelayanan kesehatan ke asuhan di komunitas harus dilaksanakan dan ditingkatkan (Wanda dkk, 2014). Sebuah studi tentang perawat kesehatan anak di komunitas melaporkan bahwa kegiatan kunjungan rumah oleh perawat memberikan manfaat yaitu dapat meningkatkan kesehatan ibu dan anak serta menjadikan keterampilan orang tua menjadi lebih baik dalam praktik perawatan anak sehingga meningkatkan interaksi antara anak dan orang tua (Henderson, 2009). Interaksi antara bayi dan kelurga terutama pada masa awal kehidupan bayi harus difasilitasi sebagai salah satu bentuk asuhan perkembangan bayi (Maryam \& Riwayati, 2018). Kehadiran perawat yang bersahabat, baik dan yang penuh perhatian dirasakan sangat bermakna bagi ibu bangsa Afrika - Amerika yang memiliki bayi umur 0-6 bulan (Coleman, 2009).

Proses membangun kerjasama antara perawat dengan keluarga di komunitas melalui tahap-tahap sebagai berikut, mengajak klien untuk ikut terlibat dalam pelayanan kesehatan anak di komunitas; memahami klien, membina rasa saling percaya dan menjalin hubungan; membangun hubungan kerja sama dengan menggunakan kekuatan dan memberikan keyakinan (Briggs, 2007).

\section{SIMPULAN}

Tradisi dan keyakinan masyarakat Bima tentang tata cara perawatan kebersihan diri bayi baru lahir berisiko merugikan kesehatan dan keamanan bayi. Diperlukan intervensi untuk menegosiasi tradisi yang melibatkan kerjasama antara tenaga kesehatan dengan keluarga sebagai unit terkecil dari masyarakat.

\section{REFERENSI}

Behrman, R.E et. al (2003). Ilmu kesehatan anak nelson. Volume 1. Jakarta : EGC

Briggs, C. (2007). Nursing practice in community child health: developing the nurse - client relationship. Journal for the Australian nursing proffesion volume 23 Issue 2 . ProQuest Nursing \& Allied Source Health.

Coleman, J.J. (2009). Culture care meanings of African American parents related to infant mortality and health care. Journal of cultural diversity volume 16 No 3. ProQuest Nursing \& Allied Source Health. 
Dahlan, M.S. (2009). Besar sampel dan cara pengambilan sampel dalam penelitian kedokteran dan kesehatan. Salemba Medika.

Douglas, MK et.al. Standards of practice for culturally competent nursing care: 2011 update. Journal of transcultural nursing. www.sagepublications.com.

Finn, Juliana dan Lee, Marilyn (2013). Transcultural nurses reflect on discoveries in china using Leininger's sunrise model. Journal of transcultural nursing. www.sagepublications.com.

Hamilton, P.M. (2009) Dasar- dasar keperawatan maternitas. Edisi 6. Jakarta : EGC

Henderson, S. (2009). Community child health nurses' experience of home visit for new mothers: a quality improvement project. Journal of the Australian nursing profession. Volume 31 Issue 1. Content management Pty Ltd. Contemporary Nurse.

Mariyam dan Riwayati. (2018). Increased the cognitive, affective and psychomotor aspect of nurse in the practice of developmental care. Media Keperawatan Indonesia Vol.1 No. Universitas Muhamadiyah Semarang.

Missal, B. (2013). Gulf Arab women's transition to motherhood. Journal of cultural diversity volume 20 Nomor 4. ProQuest Nursing \& Allied Source Health.

Neonatal Mortality formative research working group (2008). Developing community - based intervention strategies to save newborn lives: lessons learned from formative research in five countries. Journal of perinatalogy. Nature publishing group. http//www.nature.com.

Newell dan Meadow. (2005). Lecture notes: pediatrika. Penerbit Erlangga.

Nursalam. (2008). Konsep dan penerapan metodologi penelitian ilmu keperawatan, pedoman skripsi, tesis dan instrumen penelitian keperawatan edisi 2. Jakarta : Salemba Medika

Sudiharto (2007) Asuhan keperawatan keluarga dengan pendekatan keperawatan transkultural. Editor Ns. Esty Wahyuningsih.Jakarta: EGC

Wanda, D., Yustina, Y., Hayati, H., Waluyanti, F.T. (2014). Pengembangan model asuhan keperawatan bayi berat lahir rendah. Ners Journal. Volume 9 Nomor 1.

Widyastuti dan Widyani. (2008). Panduan perkembangan anak 0 sampai 1 tahun. Jakarta : Puspa Swara.

Wong, D.L. (2003). Pedoman klinis keperawatan pediatrik. Alih bahasa: Monica Ester; editor edisi bahasa Indonesia, Sari Kurnianingsih. Edisi 4. Jakarta: EGC. Hal. 226. 